\title{
Effects of Grapefruit Juice Consumption on Pharmacokinetics of Low Dose Simvastatin: Cross-over Study with a Review of the Literature
}

\section{Akira Kurata', Hiroyuki Hagiwara', Taketomo Ohmomo', Sachio Suzuki', Kuniaki Nakahara ${ }^{1}$, Shingo Konno', Chihiro Kijima ${ }^{1}$, Madoka} Inukai ${ }^{1}$, Hitoshi Ozawa' ${ }^{1}$, Kiyotaka Fujii' ${ }^{1}$ and Masataka Majima ${ }^{2}$

${ }^{1}$ Department of Neurosurgery, Kitasato University School of Medicine, Kanagawa, Japan

${ }^{2}$ Department of Pharmacology, Kitasato University School of Medicine, Kanagawa, Japan

\begin{abstract}
The effects of consumption of grapefruit juice on the pharmacokinetics of conventional low-dose simvastatin in Japan were investigated. In a randomized cross-over study with two phases, 10 healthy volunteers ingested grapefruit juice $400 \mathrm{ml}$ or water for 2 days. On day 3 , a single $5 \mathrm{mg}$ dose of simvastatin was administered with grapefruit juice $200 \mathrm{ml}$ or water. Plasma concentrations of HMG-CoA reductase inhibitor were determined up to $8 \mathrm{~h}$ thereafter. Grapefruit juice increased the area under the plasma concentration-time curves from 0 to $8 \mathrm{~h}$ of total HMG-CoA reductase inhibitor 1.7fold $(p=0.002)$ and that of active HMG-CoA reductase inhibitor 1.7-fold $(p=0.024)$. However, the peak concentrations (Cmax) and Tmax of total and active HMG-CoA reductase inhibitors were not significant influenced.Consumption of grapefruit juice with low-dose simvastatin thus resulted in mild increase of the plasma HMG-CoA reductase inhibitor, so that the pharmacokinetic interaction can be labeled as of weak CYP3A type.
\end{abstract}

\section{Introduction}

Grapefruit juice has been reported to increase plasma concentrations of calcium channel blockers [1], some HMG-CoA reductase inhibitors [2-6] and other pharmaceutical drugs, with reported selective downregulation of CYP3A4 in the duodenal epithelium where this enzyme is localized 7. Repeated consumption of high quantities of the juice is reported to elevate AUC values of lovastatin and simvastatin over 10 fold $[2,3]$ and even one glass of grapefruit juice $(200 \mathrm{ml})$, taken daily, was found to increase the area under the plasma concentration-time curves from 0-24 h [AUC (0-24)] for simvastatin 3.6 fold and for simvastatin acid 3.3 fold. The peak concentrations $(\mathrm{C}$ $\max )$ were increased 3.9 fold and 4.3 fold, respectively [5]. In Japan, the conventional dose of statin (simvastatin) applied $(5 \mathrm{mg})$ is much smaller than in Western countries (40-60mg) [3-5]. In the present study, effects of consumption of grapefruit juice on pharmacokinetics with this low dose were assessed.

\section{Materials and Methods}

\section{Subjects}

Ten healthy volunteers ( 5 men and 5 women: age range 23-35 years; weight range 43-84 kg) participated in the study. Each subject was ascertained to be in good health with reference to medical history, clinical examination, and routine laboratory testing. None were using any continuous medication, and all of them were non-smokers. The use of the grapefruit was controlled during the study according to the protocol.

\section{Study design}

A randomized crossover study design with two phases was employed with an interval of 2 weeks. The volunteers ingested $200 \mathrm{ml}$ of standard grapefruit juice (Morinaga, Tokyo, Japan) or water twice a day at 7:00 and 20:00 for two days. On the third day they received $5 \mathrm{mg}$ simvastatin (Lipovas, MSD, Tokyo, Japan) at 8:00 with $200 \mathrm{ml}$ grapefruit juice or water. The volunteers fasted overnight before administration of simvastatin, and standardized warm meal was served $3 \mathrm{~h}$ and a standardized warm light meal $7 \mathrm{~h}$ after simvastatin intake. The subjects were not allowed to drink coffee, tea, or cola during the study days.

\section{Blood sampling}

On the third study day, a plastic cannula was inserted into a forearm vein of each participant and was kept patent with an obturator. Timed blood samples were drawn into ethylenediaminetetraacetic acid (EDTA)-containing $2.5 \mathrm{ml}$ tubes before the administration of simvastatin and 1, 2, 4, and $8 \mathrm{~h}$ later. Plasma was separated within 30 min and stored at $-800^{\circ} \mathrm{C}$ until analysis.

\section{Determination of active and total HMG-CoA reductase inhibitors concentrations}

The HMG-CoA reductase inhibitory activity of the plasma samples was measured by enzymatic activity assay [8]. All plasma inhibitor concentrations are expressed in simvastatin acid equivalents.HMACoA reductase inhibitory activity in plasma was measured before and after base hydrolysis. The corresponding plasma concentration values are referred to as active and total HMG-CoA redutase inhibitor concentrations, respectively.

\section{Pharmacokinetic analysis}

The $\mathrm{C}_{\max }$ and $\mathrm{T}_{\max }$ of total HMG-CoA reductase inhibitors and active HMG-CoA reductase inhibitors were obtained directly. The terminal log-linear phase of the plasma concentaration-time curve was visually identified for each and the elimination rate constant $\left(k_{e}\right)$ was determined by linear regression analysis. The area under the plasma concentration-time curve up to the last quantified data point [AUC $(0-8 \mathrm{~h})]$ was calculated by the linear trapezoidal rule and the elimination half-life $\left(T_{1 / 2}\right)$ was determined by the equation.

$$
=\operatorname{In} 2 / k_{e}
$$

${ }^{*}$ Corresponding author: Akira Kurata, Department of Neurosurgery, Kitasato University School of Medicine, Kanagawa, Japan, E-mail: akirak@med.kitasato-u.ac.jp Received March 14, 2012; Accepted March 30, 2012; Published March 31, 2012 Citation: Kurata A, Hagiwara H, Ohmomo T, Suzuki S, Nakahara K, et al. (2012) Effects of Grapefruit Juice Consumption on Pharmacokinetics of Low Dose Simvastatin: Cross-over Study with a Review of the Literature. Med chem 2: 048050. doi:10.4172/2161-0444.1000113

Copyright: $\odot 2012$ Kurata A, et al. This is an open-access article distributed under the terms of the Creative Commons Attribution License, which permits unrestricted use, distribution, and reproduction in any medium, provided the original author and source are credited. 
Citation: Kurata A, Hagiwara H, Ohmomo T, Suzuki S, Nakahara K, et al. (2012) Effects of Grapefruit Juice Consumption on Pharmacokinetics of Low Dose Simvastatin: Cross-over Study with a Review of the Literature. Med chem 2: 048-050. doi:10.4172/2161-0444.1000113

\section{Statistical analysis}

The data are expressed as mean value $\pm \mathrm{SD}$, except for $\mathrm{T}_{\max }$, which is presented as median with range. For all variables, except for $\mathrm{T}_{\max }$ $95 \%$ confidence intervals (CI) were calculated for the mean difference between water and grapefruit juice phases. Data were analysed with the Student $t$ test (two-tailed) for paired values or, in case of $\mathrm{T}_{\max }$ by the Wilcoxon test. The statistical program Systat for Windows was for all analyses, with differences considered statistically significant at $\mathrm{p}<0.05$.

\section{Results}

\section{Total HMG-CoA reductase inhibitors}

Grapefruit juice considerably increased plasma concentrations of total HMG-CoA reductase inhibitors in each subject (Figure 1 and Table 1$)$. The mean AUC $(0-8 \mathrm{~h})$ of total HMG-CoA reductase inhibitors was increased 1.7 -fold $(\mathrm{p}=0.002)$ by ingestion of grapefruit juice compared with water (control). The mean serum concentration of total HMG-CoA reductase inhibitors after $4 \mathrm{~h}$ and $8 \mathrm{~h}$ was also increased $(\mathrm{p}<0.01)$ (Figure 1$)$, but there were no statistically significant changes in the mean $\mathrm{C}_{\max }$ and $\mathrm{T}_{\max }$ of total HMG-CoA reductase inhibitors (Table $1)$.

\section{Active HMG-CoA reductase inhibitors}

Grapefruit juice considerably increased plasma concentrations of active HMG-CoA reductase inhibitors in each subject (Figure 1 and Table 1). The mean AUC (0-8 h) of active HMG-CoA reductase inhibitors was increased 1.7 -fold $(\mathrm{p}=0.024)$ and the mean serum concentrations of active HMG-CoA reductase inhibitors were elevated after both $4 \mathrm{~h}(\mathrm{p}<0.01)$ and $8 \mathrm{~h}(\mathrm{p}<0.05)$ (Figure 1). There were no statistically significant changes in the mean $\mathrm{C}_{\max }$ and $\mathrm{T}_{\max }$ of active HMG-CoA reductase inhibitors.

\section{Discussion}

Simvastatin, lovastatin, and atorvastatin resemble each other in their sensitivity regarding interaction with CYP3A4 inhibitors. Lown et al. [2] first reported that grapefruit juice selectively down-regulates CYP3A4 in the small intestine, without any effects on liver CYP3A4. Thereby, grapefruit juice should not be consumed concomitantly with statins which need CYP3A4 for metabolism. In Japan, low- the conventional dose of simvastatin $(5 \mathrm{mg})$ is used conventionally, very much less than that in other countries (40-60 mg) because Japanese patients are more sensitive to the drug. The Japan Lipid Intervention Trial (J-LIT) study,

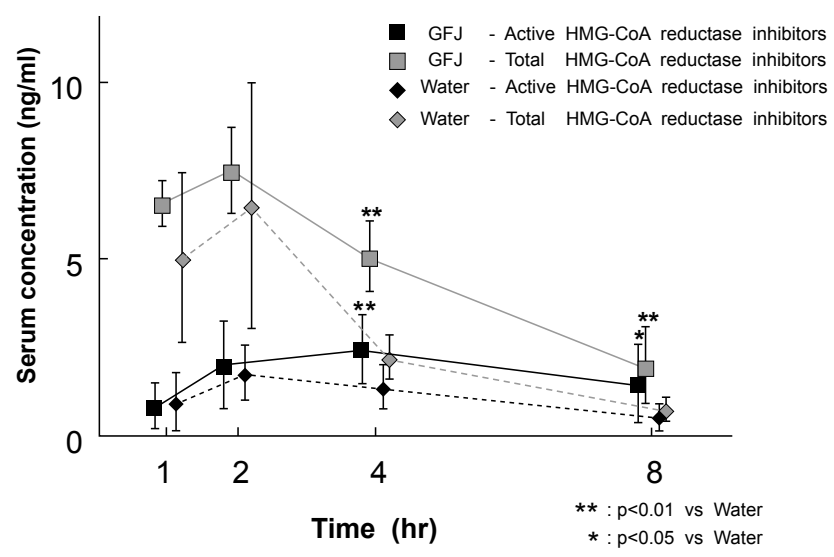

Figure 1: Mean serum concentration of active HMG- Co A reductase inhibitors and total HMG- Co A reductase inhibitors.

\begin{tabular}{|c|c|c|c|c|}
\hline & & Water & \multicolumn{2}{|c|}{ GFJ } \\
\hline & & mean $\pm S D$ & mean $\pm S D$ & $p$-value \\
\hline \multicolumn{5}{|c|}{ Active HMG-CoA reductase inhibitors } \\
\hline Cmax & (ng/mL) & $1.94 \pm 0.69$ & $2.73 \pm 1.10$ & NS \\
\hline Tmax & (hr) & $2.3 \pm 0.1$ & $3.6 \pm 1.8$ & NS \\
\hline AUC & $(0-8 \mathrm{hr})$ & $8.7 \pm 3.7$ & $14.5 \pm 6.3$ & 0.024 \\
\hline \multicolumn{5}{|c|}{ Active HMG-CoA reductase inhibitors } \\
\hline Cmax & $(\mathrm{ng} / \mathrm{mL})$ & $7.11 \pm 3.17$ & $8.54 \pm 2.89$ & NS \\
\hline Tmax & (hr) & $1.5 \pm 0.5$ & $1.8 \pm 0.9$ & NS \\
\hline AUC & $(0-8 \mathrm{hr})$ & 22.96 .7 & $38.2 \pm 11.2$ & 0.002 \\
\hline
\end{tabular}

Table 1: Pharmacokinetic parameters of active HMG-CoA reductase inhibitors and total HMG-CoA reductase inhibitors.

\begin{tabular}{|c|c|c|c|c|}
\hline $\begin{array}{l}\text { Simvastatin/ } \\
\text { Grapefruit juice/ }\end{array}$ & \multicolumn{2}{|r|}{ Cmax } & \multicolumn{2}{|c|}{ AUC } \\
\hline & W/G-Active & W/G-Total & W/G-Active & W/G-Total \\
\hline & \multicolumn{2}{|c|}{$\mathrm{ng} / \mathrm{ml}(\mathrm{p})$} & \multicolumn{2}{|c|}{$\mathrm{ng} / \mathrm{ml}(\mathrm{p})$} \\
\hline \multirow{2}{*}{ 60mg/1200ml (3) } & $3.1 / 20.3$ & $15.6 / 147.0$ & $21.7 / 147.0$ & $46.6 / 752$ \\
\hline & \multicolumn{2}{|r|}{$(p<0.001)$} & $(p<0.01)$ & $(p<0.05)$ \\
\hline \multirow{2}{*}{ 40mg/1200ml (4) } & $3.9 / 19.6$ & $9.3 / 112.0$ & $24.9 / 114.0$ & $27.8 / 373.0$ \\
\hline & \multicolumn{2}{|r|}{$(p<0.001)$} & \multicolumn{2}{|c|}{$(p<0.001)$} \\
\hline \multirow{2}{*}{ 40mg/200ml (5) } & $2.6 / 11.1$ & $7.3 / 28.5$ & $18.5 / 62.0$ & $31.6 / 112.5$ \\
\hline & & $(p<0.001)$ & \multicolumn{2}{|c|}{$(p<0.001)$} \\
\hline
\end{tabular}

W: water group, G: grapefruit juice group, Active: concentration of active simvastatin acid, Total: concentration of total simvastatin Active Inhibitors*: Active HMG-CoA reductase inhibitors Total Inhibitors*: Total HMG-CoA reductase inhibitors $\mathrm{Ng}-\mathrm{eq} / \mathrm{ml}^{* *}$ refers to the nanogram equivalents of simvastatin acid

Table 2: Review of the literature measuring active and total simvastatin level with regard to interaction of grapefruit juice with simvastatin.

\begin{tabular}{|c|c|c|c|c|}
\hline \multirow{4}{*}{$\begin{array}{l}\text { Simvastatin/ } \\
\text { Grapefruit juice/day }\end{array}$} & \multicolumn{2}{|c|}{ Cmax } & \multicolumn{2}{|c|}{ AUC } \\
\hline & W/G-Active & W/G-Total & W/G-Active & W/G-Total \\
\hline & \multicolumn{2}{|c|}{ Inhibitors* } & \multicolumn{2}{|c|}{ Inhibitors ${ }^{*}$} \\
\hline & \multicolumn{2}{|c|}{ ng-eq/ml ${ }^{* *}(p)$} & \multicolumn{2}{|c|}{ ng-eq/ml ${ }^{* *}(p)$} \\
\hline \multirow{2}{*}{$60 \mathrm{mg} / 1200 \mathrm{~m} \mathrm{(3)}$} & $21.0 / 26.8$ & $86.7 / 159$ & $88.0 / 213$ & $243 / 862$ \\
\hline & $(p<0.05)$ & $(p<0.01)$ & \multicolumn{2}{|c|}{$(p<0.01)$} \\
\hline \multirow{2}{*}{$\begin{array}{l}5 \mathrm{mg} / 400 \mathrm{ml} \text { (present } \\
\text { series) }\end{array}$} & $1.9 / 2.7$ & $7.1 / 8.5$ & $8.7 / 14.5$ & $22.9 / 38.2$ \\
\hline & \multicolumn{2}{|c|}{ (NS) } & $(p=0.024)$ & $(p=0.002)$ \\
\hline
\end{tabular}

W: water group, G: grapefruit juice group, Active Inhibitors*: active HMG-CoA reductase inhibitors, Total Inhibitors*: total HMG-CoA reductase inhibitors $\mathrm{Ng}-\mathrm{eq} / \mathrm{ml} \mathrm{l}^{* *}$ refers to the nanogram equivalents of simvastatin acid

Table 3: Review of the literature measuring HMG-CoA reductase inhibitors level with regard to interaction of grapefruit juice with simvastatin.

a nationwide cohort study, showed $5 \mathrm{mg} /$ day to effectively control the serum total cholesterol and low density lipoprotein-cholesterol concentrations by reducing them by approximately $20 \%$ on average in hypercholesterolemic Japanese patients, a reduction that corresponds to the effect of $20 \mathrm{mg} /$ day in Western studies [9]. The effect of regular consumption of grapefruit on the phamacokinetics of low-dose of simvastatin has not attracted attention in the past (Table 2)[3-5]. The With a high-dose $(40 \mathrm{mg})$ of simvastatin, where even a once daily a glass of grapefruit juice $(200 \mathrm{ml})$ has been reported to increase simvastatin and simvastatin acid AUC 3.4-3.6 fold and $C_{\max } 3.9-4.3$ fold [5] or and high quantities of grapefruit juice $(1200 \mathrm{ml} /$ day) result in much greater levels for AUC ( 4.6-13.4 fold) and $\mathrm{C}_{\max }$ (5.0-12.0 fold) [3,4].

Lilja et al. [3] has measured also HMG-CoA reductase inhibitory activity. They reported grapefruit juice significantly increased the serum concentrations of HMG-CoA reductase inhibitors (Table 3), but the effect was less than that on serum simvastatin and simvastatin acid (Table 2). The mean AUC of active inhibitors was increased 2.4- 
fold $(\mathrm{p}<0.01)$ by grapefruit juice (Table 3$)$. The mean Cmax of total inhibitors was increased 1.8 -fold $(\mathrm{p}<0.01)$ and the mean AUC was increased 3.6-fold. The data from the present study also, the enzyme inhibition assay, clearly indicate that even $5 \mathrm{mg}$ simvastatin with grapefruit juice twice daily (total: $400 \mathrm{ml}$ ) increases the mean AUC of active and total inhibitors (1.7 fold). Liu et al reported [8] the enzyme inhibition assay, which measures overall inhibitory activity from active and potentially active metabolites, is therefore, a preferred assay method for pharmacokinetic, bioavailability, and drug interaction studies. The FDA recommends that a 2-5 fold increase in AUC is moderate and most likely to be without any clinical relevance, while an increase $>5$ points indicates a severe interaction which will have clinical consequences. Between 1.25- and 2-fold, it can be labeled as of weak CYP3A inhibitor type [10]. Consumption of grapefruit juice (400 ml/day) with lowdose simvastatin $(5 \mathrm{mg}$ ) caused a mild increase (1.7 fold) of the plasma HMG-CoA reductase inhibitor, so that the pharmacokinetic interaction can be labeled as of weak CYP3A inhibitor type. A rise in the actual in vivo dose of simvastatin has reported to increase the risk of skeletal muscle toxicity [11], myopathy or rhabdomyolysis occurring at incidences of $0.02 \%, 0.08 \%$, and $0.53 \%$, respectively, with 20,40 , and $80 \mathrm{mg}$ daily, with high dose simvastatin at $80 \mathrm{mg}$ in another study [12], muscle toxicity not appear even with an AUC of $190 \mathrm{ng} / \mathrm{ml}$ for active simvastatin and $568 \mathrm{ng} / \mathrm{ml}$ for total simbastatin The Cmax of active simvastatin acid is $43 \mathrm{ng} / \mathrm{ml}$ and total simvastatin is $179 \mathrm{ng} / \mathrm{ml}$. In the present study, low dose of simvastatin with regular consumption of grapefruit juice, the AUC of active HMG-CoA reductase inhibitors was $14.5 \mathrm{ng} \mathrm{eq} / \mathrm{ml}$ and total HMG-CoA reductase inhibitors was $38.2 \mathrm{ng} \mathrm{eq} /$ $\mathrm{ml}$, with $\mathrm{C}_{\max }$ values of $2.73 \mathrm{ng} / \mathrm{ml}$ and $8.54 \mathrm{ng}$ eq/ml, respectively. Low dose of simvastatin with regular consumption of grapefruit juice did not induce the high level of the active and total HMG-CoA reductase inhibitors compared with high dose of simvastatin [3] because the control serum value was low. The serum pharmacokinetic our data of $5 \mathrm{mg}$ oral dosesof simvastatin concomitant with $400 \mathrm{ml}$ grapefruit juice corresponded to almost 1/3rd [13] to 1/5th [14] of the HMG-CoA reductase inhibitory activity which has been already reported with a 40 mg oral dose of simvastatin only. The risk of skeletal muscle toxicity should therefore be limited for patients taking a low dose of simvastatin concomitant with regular consumption of grapefruit juice.

The authors declared no conflict of interest.

\section{Acknowledgement}

The authors thank Dr. Malcolm Moore for editing the manuscript.

\section{References}

1. Bailey DG, Spence JD, Munoz C, Arnold JMO (1991) Interaction of citrus juices with felodipine and nifedipine. Lancet 337: 268-269.

2. Kantola, T, Kivisto, K, Neuvonen PJ (1998) Grapefruit juice greatly increases serum concentrations of lovastatin and lovastatin acid. Clin Phamacol Ther 63 397-402.

3. Lilja JJ, Kivisto KT, Neuvonen PJ (1998) Grapefruit juice-simvastatin interaction effect on serum concentration of simvastatin, simvastatin acid, and HMG-CoA reductase inhibitors. Clin Phamacol Ther 64: 477-483.

4. Lilja JJ, Kivisto KT, Neuvonen PJ (2000) Duration of effect of grapefruit juice on the CYP3A4 substrate simvastatin. Clin Phamacol Ther 68: 384-390.

5. Lilja JJ, Neuvonen M, Neuvonen PJ (2004) Effects of regular consumption of grapefruit juice on the phamacokinetics of simvastatin. Br J Clin Pharmacol 58:56-60.

6. Lilja JJ, Kivisto KT, Neuvonen PJ (1999) Grapefruit juice increases serum concentrations of atorvastatin and has no effect on pravastatin. Clin Phamacol Ther 66: 118-127.

7. Lown KS, Bailey DG, Fontana RJ, Janardan SK, Adair CH, et al. (1997) Grapefruit juice increases felodipine oral availability by decreasing intestinal CYP3A protein expression. J Clin Invest 99: 2545-2553.

8. Liu L, Zhang R, Zhao JJ, Rogers JD, Hsieh JY et al. (2003) Determination of simvastatin-derived derived HMG-CoA reductase inhibitors in biomatrices by an automated enzyme inhibition assay with radioactivity detection. J Pharm Biomed Anal 32: 107-123.

9. Matsuzawa $\mathrm{Y}$, Kita T, Mabuchi H, Matsuzaki M, Nakaya N et al. (2003) Sustained reduction of serum choresterol in low-dose 6-year simvastatin treatment with minimum side effects in 51,321 Japanese hypercholesterolemic patients. Circ J 67: 287-294.

10. Guidance for Industry. Drug interaction studies-study design, data analysis, and implications for dosing and labering (2006).

11. Backes JM, Howard PA, Ruisinger JF, Moriarty PM (2009) Does simvastatin cause more myotoxity compared with other statins? Ann Phamacother 43: 2012-2020.

12. Bergman AJ, Murphy G, Burke J, Zhao JJ, Valesky R, et al. (2004) Simvastatin does not have a clinically significant pharmacokinetic interaction with fenofibrate in humans. J Clin Phamacol 44: 1054-1062.

13. Pentikainen PJ, Saraheimo M, Schwartz JI, Amin RD, Schwartz MS, et al. (1992) Comparative pharmacokinetics of lovastatin, simvastatin and pravastatin in humans. J Clin Pharmacol 32: 136-140.

14. Cheng H, Rogers JD, Sweany AE, Dobrinska MR, Stein EA, et al. (1992) Influence of age and gender on the plasma profiles of 3-hydroxy-3 methylgultaryl-coenzyme A (HMG-CoA) reductase inhibitory activity following multiple doses of Ivastatin and simvastatin. Pharm Res 12: 1629-1633. 